\title{
Uso sustentable de productos forestales no maderables en la Amazonía Ecuatoriana: Una oportunidad para el desarrollo armónico
}

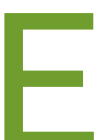
n el mundo actual, aún en medio de una pandemia que asoló a la humanidad, y a los graves problemas ambientales que se avecinan, es urgente la búsqueda de opciones para el desarrollo sustentable de todo el complejo humano. Las respuestas pasan por revalorizar la funcionalidad ecosistémica de los bosques y por buscar alternativas para generar un desarrollo basado en una bioeconomía sustentable.

Hace pocos meses se firmo el Pacto Nacional para la Bioeconomía sustentable en Ecuador, que en su introducción establece: La Bioeconomía para el Ecuador representa una estrategia alternativa de desarrollo basado en la orientación de las actividades económicas enfocadas en la generación de conocimiento, uso y aprovechamiento sostenible de los recursos naturales de la biodiversidad, agro- biodiversidad y sus derivados, a través de un conjunto de políticas, procesos productivos y prácticas fundamentadas en la creación y transferencia de conocimiento, innovación y nuevas tecnologías, que provean productos y servicios, contribuyendo así en la transición hacia un sistema económico sostenible, socialmente inclusivo, competitivo y resiliente ${ }^{1}$.

Los productos forestales no maderables (PFNM's) son aquellos derivados de ecosistemas forestales, diferentes a la madera, que prestan otros servicios y productos importantes a las comunidades que habitan en éstos. Existe una gran diversidad de productos que incluyen semillas y frutos alimenticios, fibra para construcción de estructuras, esencias, aromas y resinas; colorantes y especies medicinales. Gran parte de la riqueza originaria de nuestros bosques pasa por la existencia de una cantidad importante de estos productos, los cuales fueron adoptados por las culturas originarias; quienes encontraron en estos parte de su sustento

Sin embargo, la paulatina deforestación con fines de extracción maderera; o para generar cultivos extensivos, en el caso de Ecuador, palma aceitera, café y cacao, entre otros; y la ganadería que ocupa cada vez más espacios boscosos ha hecho que los PFNM's no ganen la relevancia suficiente $y$, que incluso, pasen a estar en categoría de peligro por causa de estas formas de explotación ecológica. En este entorno, es importante desde la investigación generar programas que permitan la búsqueda de aplicaciones de estos productos para que puedan ingresar al mercado actual, o generar usos sustentables de esta enorme diversidad de bienes que nos ofrecen los bosques.

Es por esto que en el contexto de Ecuador, a través de los Ministerios de Ambiente, Agua y Transición Ecológica y Ministerio de Agricultura y Ganadería se estableció el programa PROAmazonía, cuyo uno de sus objetivos es el desarrollo de cadenas de valor libres de deforestación, a partir de cultivos ya existentes y también de productos forestales no maderables.

Bajo esta situación, la Universidad Técnica Particular de Loja busca a través del proyecto "Asistencia técnica para la identificación de oportunidades de negocio a partir de PFNMS, productos de la biodiversidad, MFS/MST y factibilidad de planta para aprovechamiento sustentable en la Amazonía Centro y Sur, bajo el marco del programa PROAmazonía", la generación de alternativas viables para comunidades de la Amazonía Ecuatoriana en torno al uso ustentable de Productos Forestales No Maderables.

Es así que se ha dedicado este número especial de la revista Bionatura a formular un marco de colaboración nacional para la identificación de investigaciones alrededor de PFNM en todo el Ecuador, para así dejar patentes las oportunidades de negocios sustentables con las que cuentan nuestros bosques, las cuales podemos transferir a las comunidades locales, en búsqueda de llegar a un desarrollo sustentable; y la importancia de que la investigación genere lazos con el contexto y ganen en relevancia y pertinencia.

\section{Referencias bibliográficas}

1. Gobierno del Ecuador. Pacto Nacional para la Bioeconomía Sustentable, (2021). Disponible en https://wwflac.awsassets.panda.org/downloads/pacto_nacional_por_la_bioeconomia_texto_definitivo.pdf 


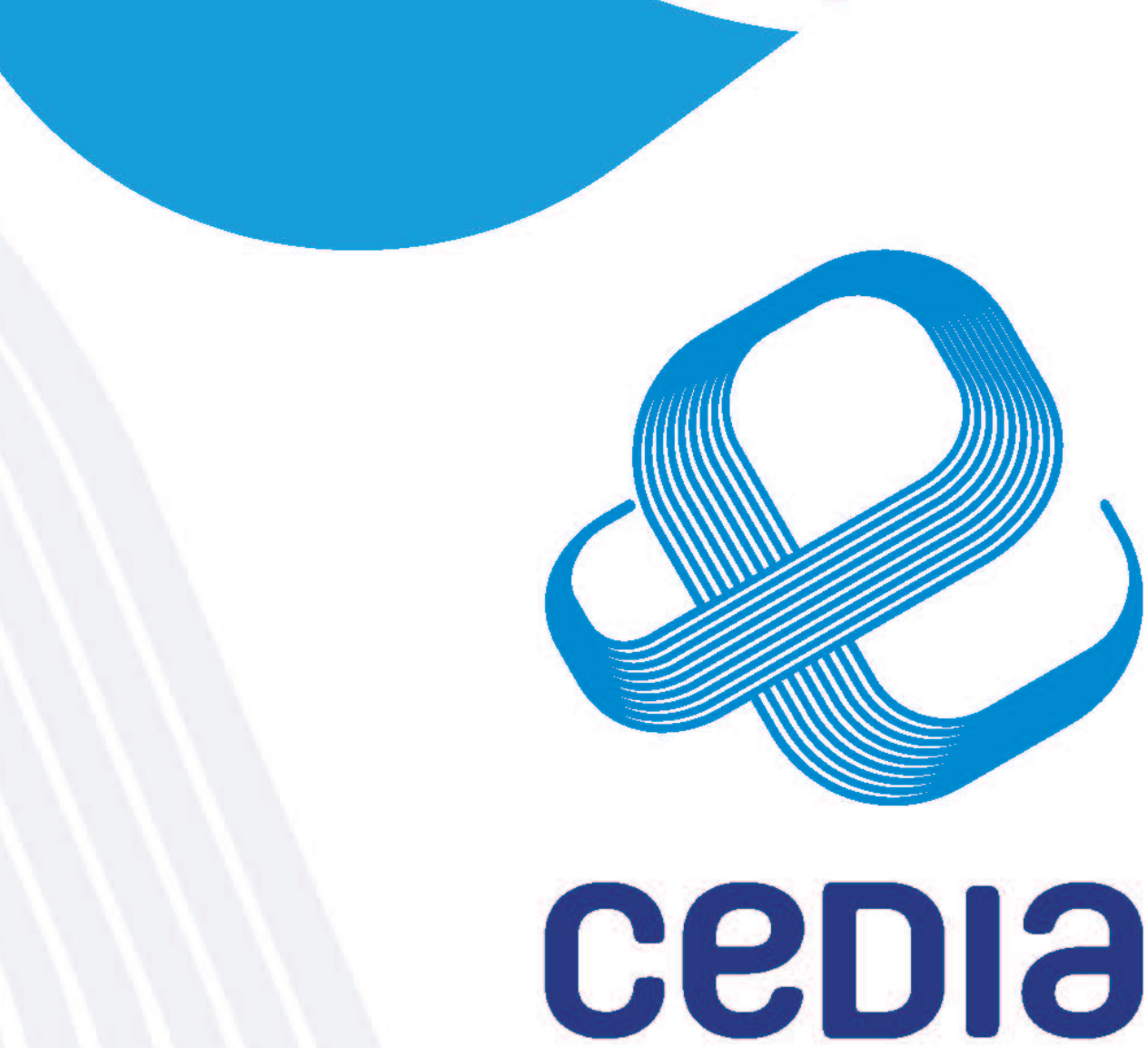

CORPORACIÓN ECUATORIANA PARA EL DESARROLLO DE LA INVESTIGACIÓN YLAACADEMIA

$\frac{\theta \rightarrow f y \text { in }}{\text { CEDIAec }}$

\section{ww w. cedia.edu.ec}

